\title{
Исследование влияния сурфактанта Ga при высокотемпературной аммиачной молекулярно-лучевой эпитаксии слоев AIN на свойства нитридных гетероструктур
}

\author{
(C) А.Н. Алексеев, В.В. Мамаев, С.И. Петров
}

$3 \mathrm{AO}$ „HTO", 194156 Санкт-Петербург, Россия

E-mail: petrov@semiteq.ru

(Получена 27 апреля 2017 г. Принята к печати 12 мая 2017 г.)

\begin{abstract}
Представлены результаты выращивания буферных слоев AlN для транзисторов с высокой подвижностью электронов методом высокотемпературной аммиачной молекулярно-лучевой эпитаксии с использованием $\mathrm{Ga}$ в качестве сурфактанта. Основными параметрами, влияющими на кинетику роста и дефектообразование, являются эффективные потоки прекурсоров и сурфактанта, а также температура подложки, которая ограничивает поток сурфактанта из-за десорбции $\mathrm{Ga}$ с поверхности. В частности, добавление потока $\mathrm{Ga}$, равного потоку $\mathrm{Al}$, при температуре подложки $1150^{\circ} \mathrm{C}$ не изменяет скорость роста, меняя при этом его кинетику. Такой подход позволяет повысить поверхностную подвижность адатомов и обеспечивает быстрый переход в режим 2D-роста. В гетероструктурах с двумерным электронным газом, выращенных с использованием сурфактанта, была достигнута подвижность носителей до $2000 \mathrm{~cm}^{2} / \mathrm{B} \cdot \mathrm{c}$.
\end{abstract}

DOI: 10.21883/FTP.2017.11.45100.14

\section{1. Введение}

Среди всего спектра материалов особый интерес представляют нитриды металлов III группы $\left(\mathrm{A}^{\mathrm{III}} \mathrm{N}\right)$, так как они обладают уникальными свойствами и интенсивно исследуются с целью создания оптоэлектронных и СВЧ мощных высокотемпературных приборов на их основе. Введение сурфактанта — вещества, находящегося на ростовой поверхности и при этом не участвующего в росте пленки, - меняет кинетику адатомов, увеличивая их поверхностную подвижность. При небольшом потоке аммиака и температуре выше $1000^{\circ} \mathrm{C}$ рост нитрида галлия невозможен, поэтому галлий может выступать в качестве сурфактанта для роста слоев AlN. Важными параметрами, определяющими механизмы роста и дефектообразования, являются эффективные потоки компонентов растущей пленки и сурфактанта. При этом температура подложки влияет на скорость десорбции галлия с поверхности, что накладывает ограничение на поток галлия.

Отсутствие дешевых, согласованных по параметру решетки, подложек приводит к высокой плотности дислокаций в выращиваемых слоях, несмотря на применение специальных процедур на начальных стадиях роста. Более того, характерные температуры роста в МЛЭ значительно ниже по сравнению с МОГФЭ. Это приводит к недостаточной поверхностной подвижности атомов и худшему сращиванию зародышевых блоков на начальной стадии роста, что в свою очередь приводит к увеличению плотности дислокаций. Плотность дислокаций в $\mathrm{GaN}$, выращенных методом МОГФЭ, находится в диапазоне $10^{8}-10^{9} \mathrm{~cm}^{-2}\left(10^{7} \mathrm{~cm}^{-2}\right.$ с использованием технологии ELOG), в то же время для МЛЭ это значение находится в диапазоне $10^{9}-10^{10} \mathrm{~cm}^{-2}$, что приводит к меньшим значениям подвижности в $\mathrm{GaN}$, выращенном МЛЭ, по сравнению с МОГФЭ. Типичные значения подвижно- сти электронов в слоях $\mathrm{GaN}$, выращенных методом МЛЭ на сапфире или $\mathrm{SiC}$ с использованием различных буферных слоев (обычно $\mathrm{GaN}, \mathrm{AlGaN}$ или $\mathrm{AlN}$ толщиной менее $50 \mathrm{Hм}$ ), составляют $250-350 \mathrm{~cm}^{2} / \mathrm{B} \cdot \mathrm{c}$, а для МОГФЭ - 500-700 $\mathrm{cm}^{2} / \mathrm{B} \cdot$ с. Рекордные значения составляют $560 \mathrm{~cm}^{2} / \mathrm{B} \cdot \mathrm{c}$ (с использованием буферного слоя AlN, полученного при помощи магнетронного распыления) и $900 \mathrm{~cm}^{2} / \mathrm{B} \cdot$ с для МЛЭ и МОГФЭ соответственно [1,2]. Путем оптимизации условий МЛЭ роста в слоях $\mathrm{GaN}$, выращенных МОГФЭ „темплейтах“, были получены значения подвижности электронов более $1100 \mathrm{~cm}^{2} / \mathrm{B} \cdot \mathrm{c}[3]$.

Цель настоящей работы состояла в исследовании влияния Ga как сурфактанта при выращивании методом высокотемпературной аммиачной молекулярно-лучевой эпитаксии (МЛЭ) слоев AlN на свойства нитридных гетероструктур, выращенных на них.

\section{2. Экспериментальная часть}

Гетероструктуры на основе $\mathrm{GaN}$ были выращены на подложках $\mathrm{Al}_{2} \mathrm{O}_{3}$ (0001) в Прикладной лаборатории $3 \mathrm{AO}$ „НТО“ на установках МЛЭ серии STE3N российского производства, выпускаемых $3 \mathrm{AO}$ „НТО“ под торговой маркой SemiTeq. Уникальными особенностями данного оборудования являются значительно расширенный диапазон рабочих температур подложки и отношений потоков $\mathrm{B}^{\mathrm{V}} / \mathrm{A}^{\mathrm{III}}$. В частности, благодаря криопанелям увеличенной площади и усиленной системе откачки в ростовой камере обеспечивается вакуум не хуже $5 \cdot 10^{-3}$ Па при увеличении температуры подложки до $970^{\circ} \mathrm{C}$ при потоке аммиака $400 \mathrm{~cm}^{3} /$ мин. В результате дополнительной модернизации узла нагрева образца и ростового манипулятора обеспечивается возможность длительного роста с вращением на подложках диамет- 
ром до 100 мм при температуре до $1200^{\circ} \mathrm{C}$ (показания пирометра). При этом вакуум находится на уровне не хуже $1 \cdot 10^{-3}$ Па (при потоке аммиака $60 \mathrm{~cm}^{3} /$ мин).

В качестве инструментов для in situ контроля скорости роста и состояния ростовой поверхности использовалась лазерная интерферометрия и дифракция быстрых электронов на отражение (RHEED). Свойства выращенных образцов исследовались при помощи просвечивающей электронной микроскопии (ТЕМ) и холловских измерений.

\section{3. Результаты и обсуждение}

Ранее нами было показано, что использование высокотемпературных буферных слоев AlN/сверхрешетка/AlGaN, выращенных методом МЛЭ с использованием аммиака в качестве источника азота при экстремально высокой температуре подложки (до $1150^{\circ} \mathrm{C}$ ), позволяет кардинально улучшить структурное совершенство слоев $\mathrm{GaN}$ [4]. Плотность дислокаций в $\mathrm{GaN}$ была понижена до значений $9 \cdot 10^{8}-1 \cdot 10^{9} \mathrm{~cm}^{-2}$ (рис. 1). Уменьшение плотности дислокаций привело к значительному увеличению подвижности электронов в слоях $\mathrm{GaN}$. Максимальная подвижность электронов в слабо легированном кремнием слое $\mathrm{GaN}$ толщиной 1.5 мкм находится на уровне $600-650 \mathrm{~cm}^{2} / \mathrm{B} \cdot \mathrm{c}$ при концентрации электронов $3-5 \cdot 10^{16} \mathrm{~cm}^{-3}$. Полученные значения плотности дислокаций и подвижности электронов в слоях $\mathrm{GaN}$ являются лучшими на сегодняшний день для метода МЛЭ и находятся в числе лучших для метода МОГФЭ. Экспериментальные значения подвижности и плотности дислокаций согласуются с данными расчетов [5].

Важно отметить, что получение таких буферных слоев трудно реализовать в плазменной МЛЭ, поскольку для двумерного режима роста AlN необходим Al-обогащенный режим, а десорбция алюминия становится существенной при температуре подложки более $900^{\circ} \mathrm{C}$.

Использование указанных слоев $\mathrm{GaN}$ в двойной гетероструктуре с барьерным слоем $\mathrm{Al}_{x} \mathrm{Ga}_{1-x} \mathrm{~N}$ различного состава $(x=0.25-0.4)$ позволило контролируемо изменять слоевое сопротивление, концентра-

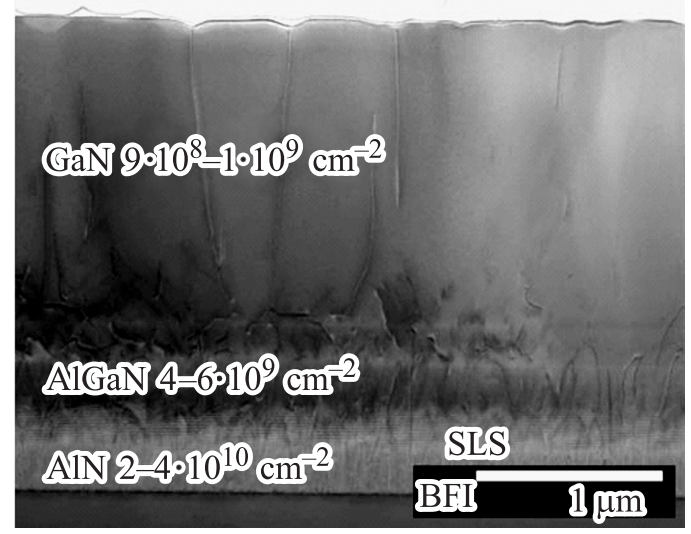

Рис. 1. STEM-изображение многослойной гетероструктуры. цию и подвижность в двумерном электронном газе в диапазоне $230-400$ Ом/ед.пл., $(1.0-1.8) \cdot 10^{13} \mathrm{~cm}^{-2}$ и $1300-1700 \mathrm{~cm}^{2} / \mathrm{B} \cdot$ с соответственно, на подложках сапфира и $\mathrm{SiC}$. При этом барьерный слой состоял из тонкого слоя AlN толщиной 1 нм и модулировано легированного кремнием слоя $\mathrm{AlGaN}$ толщиной 24 нм.

В настоящей работе было исследовано влияние потока сурфактанта $\mathrm{Ga}$ и температуры подложки при выращивании буферного слоя AlN на свойства гетероструктуры AlN/AlGaN/GaN/AlGaN. Было проведено выращивание нескольких серий гетероструктур с двумерным газом стандартной конструкции, отличающихся потоком сурфактанта Ga при росте слоя AlN. Рассмотрено влияние соотношения потоков $\mathrm{Al}$ и $\mathrm{Ga}$ в диапазоне от 20:1 до $1: 1$ при температурах подложки от 1050 до $1150^{\circ} \mathrm{C}$. При этом необходимо отметить, что данные соотношения потоков являются достаточно условными, поскольку определялись по скорости роста при температуре подложки менее $800^{\circ} \mathrm{C}$, при которой десорбция с поверхности и термическое разложение нитрида галлия не так существенны. При температурах выше $1000^{\circ} \mathrm{C}$ и небольшом потоке аммиака $\left(60 \mathrm{~cm}^{3} / \mathrm{Mин}\right)$ скорость термического разложения нитрида галлия существенно выше скорости его роста, кроме того, становится существенной десорбция металлов (в большей степени $\mathrm{Ga}$ ) с поверхности. Таким образом, реальное соотношение потоков $\mathrm{Al}: \mathrm{Ga}$ при температурах подложки $1050-1150^{\circ} \mathrm{C}$ заметно выше и существенно отличается от температуры $800^{\circ}$ С. Было установлено, что даже использование равных потоков $\mathrm{Al}$ и $\mathrm{Ga}$ не приводит к изменению скорости роста AlN при температуре подложки $1150^{\circ} \mathrm{C}$, что говорит о том, что атомы галлия не встраиваются в решетку AlN, при этом обеспечивается ускоренный переход в двумерный режим роста. При температуре подложки $1050^{\circ} \mathrm{C}$ и отношениях потоков алюминия и галлия 1:1-2:1 наблюдается небольшое увеличение скорости роста AlN. На рис. 2 представлена картина дифракции быстрых электронов на отражение (RHEED) во время роста слоя AlN при различных соотношениях потоков $\mathrm{Al} / \mathrm{Ga}$ при температуре $1150^{\circ} \mathrm{C}$.

Видно, что наиболее быстрый переход к двумерной картине роста происходит при соотношении потоков около 10:1. Эти данные коррелируют с данными подвижности в двумерном электронном газе (рис. 3). Для сравнения на рисунке также представлены значения подвижности электронов в гетероструктуре, выращенной без использования сурфактанта (для наглядности точка обозначена на рисунке как точка, соответствующая отношению потоков $100: 1)$.

Следует отметить, что при повторных экспериментах для одних и тех же значений отношения $\mathrm{Al}: \mathrm{Ga}$ наблюдался определенный разброс значений подвижности, а на графике приведены максимальные полученные значения. При этом можно заключить, что подвижность в двумерном электронном газе в гетероструктурах AlN/AlGaN/GaN/AlGaN, выращенных при тепмператуpe $1150^{\circ} \mathrm{C}$ с использованием сурфактанта, на $10-30 \%$ 


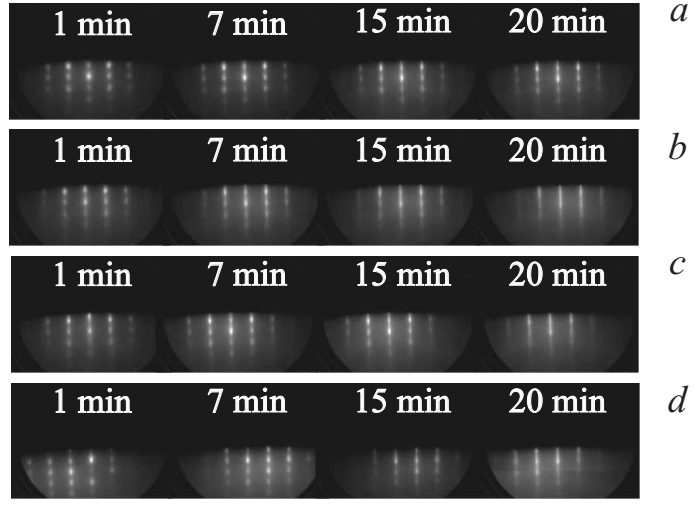

Рис. 2. Картина дифракции быстрых электронов на отражение (RHEED) во время роста слоя AIN при различных соотношениях потоков $\mathrm{Al} / \mathrm{Ga}$ при температуре $1150^{\circ} \mathrm{C}: a-$ без $\mathrm{Ga}$, $b-10: 1, c-2: 1, d-1: 1$. Указано время с момента начала роста, поток алюминия соответствует скорости роста 0.2 мкм/ч.

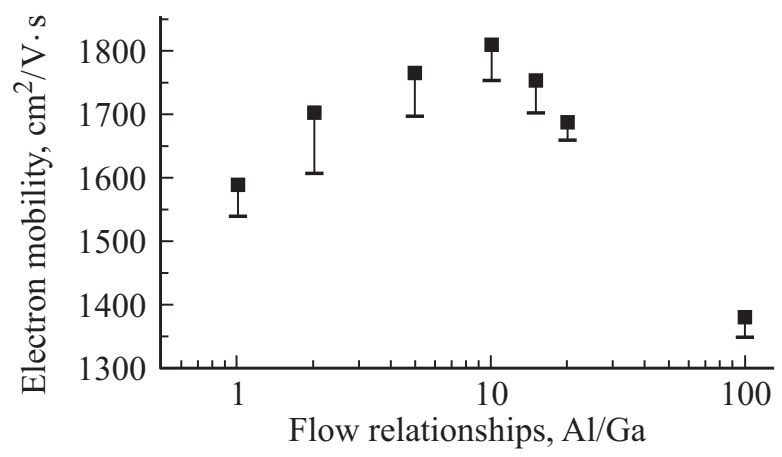

Рис. 3. Зависимость подвижности в двумерном газе $\mathrm{GaN} / \mathrm{AlGaN}$ в гетероструктуре AlN/AlGaN/GaN/AlGaN от соотношения потоков алюминия и сурфактанта $\mathrm{Ga}$ в течение роста буферного слоя AlN. Указана максимальная подвижность электронов.

выше, чем в аналогичных структурах без сурфактанта, а оптимальное соотношение потоков $\mathrm{Al}: \mathrm{Ga}$ находится в диапазоне от 15 до 5. При использовании других температур подложки оптимальный диапазон будет отличаться. Уменьшение температуры подложки приведет к уменьшению десорбции галлия и соответственно к увеличению оптимального соотношения $\mathrm{Al}: \mathrm{Ga}$.

Максимальная подвижность в двумерном электронном газе $1800 \mathrm{~cm}^{2} / \mathrm{B} \cdot \mathrm{c}$ при концентрации $1.4 \cdot 10^{13} \mathrm{~cm}^{-2}$ была получена при соотношении потоков алюминия к галлию 10:1. При понижении концентрации в двумерном электронном газе до $1.0 \cdot 10^{13} \mathrm{~cm}^{-2}$ за счет понижения уровня легирования была получена подвижность до $2000 \mathrm{~cm}^{2} / \mathrm{B} \cdot$ с. В настоящее время проводятся исследования плотности дислокаций в гетероструктурах, полученных с использованием сурфактанта.

\section{4. Заключение}

Использование высокотемпературных буферных слоев AlN позволяет значительно улучшить структурное совершенство нитридных гетероструктур и повысить подвижность электронов в слоях $\mathrm{GaN}$. Для дальнейшего улучшения качества слоев было предложено использовать Ga как сурфактант при высокотемпературной эпитаксии AlN методом аммиачной МЛЭ. Ключевыми параметрами, определяющими кинетику роста и дефектообразование, являются эффективные потоки прекурсоров и сурфактанта, а также температура подложки. Установлено, что использование сурфактанта Ga при высокотемпературной аммиачной MЛЭ AIN позволяет на 10-30\% увеличить подвижность в двумерном электронном газе в гетероструктурах, выращенных при температуре подложки $1150^{\circ} \mathrm{C}$, а оптимальное соотношение потоков $\mathrm{Al}: \mathrm{Ga}$ находится в диапазоне от 15 до 5. В гетероструктурах с двумерным электронным газом GaN/AlGaN была получена подвижность электронов до $2000 \mathrm{~cm}^{2} / \mathrm{B} \cdot \mathrm{c}$.

Работа выполнена при финансовой поддержке гранта РФФИ 14-41-08048 р_офи_м и Программы стратегического развития БГТУ им. В.Г. Шухова на 2012-2016 годы.

\section{Список литературы}

[1] J.B. Webb, H. Tang, J.A. Bardwell, S. Moisa, C. Peters, T. MacElwee. J. Cryst. Growth, 230 (3), 584 (2001).

[2] S. Nakamura, T. Mukai, M. Senoh. J. Appl. Phys., 71 (11), 5543 (1992).

[3] G. Koblmüller, F. Wu, T. Mates, J.S. Speck, S. FernándezGarrido, E. Calleja. Appl. Phys. Lett., 91, 221905 (2007).

[4] S.I. Petrov, A.N. Alexeev, D.M. Krasovitsky, V.P. Chaly. Phys. Status Solidi C, 9 (3-4), 562 (2012).

[5] H.M. Ng, D. Doppalapudi, T.D. Moustakes. Appl. Phys. Lett., 73 (6), 821 (1998).

Редактор Г.А. Оганесян

\section{Study of the influence of Ga as surfactant on properties of nitride heterostructures grown by high temperature ammonia MBE of AIN layers}

\author{
A.N. Alexeev, V.V. Mamaev, S.I. Petrov \\ SemiTEq JSC, \\ 194156 St. Petersburg, Russia
}

Abstract In this work we present the results of AlN buffer layer ammonia MBE growth for HEMT using Ga as surfactant. Key parameters that affect the growth kinetics and defects formation are efficient fluxes of precursors and surfactant as well as the substrate temperature which limits surfactant flux because of desorption $\mathrm{Ga}$ from the surface. In particular, addition of $\mathrm{Ga}$ flux equal to $\mathrm{Al}$ flux at substrate temperature $1150^{\circ} \mathrm{C}$ keeps the growth rate constant. This approach allows to increase surface mobility of adatoms, provides quick transition to 2D-growth mode, that results in mobility increasing in GaN bulk layer as well as in heterostructures with 2DEG. In GaN/AlGaN heterostructures mobility up to $2000 \mathrm{~cm}^{2} / \mathrm{V} \cdot \mathrm{s}$ was achieved. 